TOBY BETENSON

University of Birmingham

\title{
Bradley Monton. Seeking God in Science: An Atheist Defends Intelligent Design. Peterborough, Ont.: Broadview, 2009.
}

Bradley Monton's Seeking God in Science: An Atheist Defends Intelligent Design is a bold attempt to abstract the arguments of Intelligent Design (ID) beyond the embattled cultural and political context that has granted the theory such notoriety, and assess the central claims of the theory dispassionately. What are the claims of ID, what are the arguments to support them, and are these good arguments? Monton feels that, as a philosopher, these are the terms on which the theory should be judged; the "culture war" (p. 12) should be ignored. Although Monton is not persuaded by the arguments, he does consent that they are "somewhat plausible" (p. 75), causing him to be less certain of his atheism than he would have been had he not heard the arguments.

He begins by seeking a clear understanding of ID's claims in Chapter One: "What Is Intelligent Design, and Why Might an Atheist Believe in It?" After a prolonged, and occasionally simplistic, discussion of what ID cannot be claiming, we finally come to Monton's version of ID:

The theory of intelligent design holds that certain global features of the universe provide evidence for the existence of an intelligent cause, or that certain biologically innate features of living things provide evidence for the doctrine that the features are the result of the intentional actions of an intelligent cause which is not biologically related to the living things, and provide evidence against the doctrine that the features are the result of an undirected process such as natural selection. (p. 39)

Monton has tried very hard to formulate a statement of ID that accurately captures the claims of ID whilst ruling out any awkwardly simple ways in which the claims can be made trivially true. His is certainly an improvement on the Discovery Institute's statement: "The theory of intelligent design holds that certain features of the universe and of living things are best explained by an intelligent cause, not an undirected process such as natural selection." (p. 16) Monton correctly identifies 
that this can be made trivially true in such mundane circumstances as the construction of buildings, but does such mundane clarification need to be made? Perhaps it's too simple to state that 'everyone knows' what the claims of ID are, and it is legitimate and admirable to try and isolate the actual claims of ID from potentially misleading preconceptions, but Monton's philosophically rigorous formulation is noticeably selective and betrays his own intentions. He is balancing between, on the one hand, retaining an authentic and accurate version of ID's claims, whilst on the other preserving the possibility of a non-theistic, strictly 'natural' solution. Each refinement across the 25 page section within the first chapter moulds the ultimate statement into a 'just right' balance between being complicated enough to rule out trueness by triviality, whilst simultaneously refraining from going all the way to a full-fledged statement of supernatural theism.

Monton's claim is that ID is not inherently theistic; at the end of chapter one he argues for this claim:

It is true that almost all proponents of intelligent design believe in a supernatural creator, but it doesn't follow that the thesis that there is a supernatural creator is part of the intelligent design doctrine itself. The intelligent design proponents ... have chosen to put forth their doctrine in such a way that it involves some sort of commitment to an intelligent cause, without specifying whether that intelligent cause is supernatural. (p. 41, emphasis added)

But have they chosen to put forth their doctrine in such a way, or has Monton chosen to formulate it so? Is intelligent design, as a matter of fact, not inherently theistic? We may grant that it is not necessarily so, but perhaps there is a recognisable difference between what ID proponents could say and what they do say. Monton ignores what might be termed the 'brute facts of the matter' - namely that ID is considered by many to demonstrably be 'creationism in disguise' - leading him to defend a version of ID that perhaps not even ID proponents would endorse.

The claim that ID is not necessarily inherently theistic is important to Monton for two reasons: Firstly, surrendering the inherent requirement of a necessarily supernatural solution (i.e. God) preserves the status of ID as being 'legitimate' science. Secondly, he needs this claim to be true in order to isolate the arguments of ID from its cultural context of 'merely 
religious creationism in disguise.' In chapter two, "Why It Is Legitimate to Treat Intelligent Design as Science", he takes up these issues via a discussion of the Kitzmiller v. Dover Area School District case. Monton is very critical of the ruling cast by judge John E. Jones III (judge Jones decided that "intelligent design counts as religion, not science, and hence the teaching of intelligent design in public school is unconstitutional" (p. 48)). Monton claims the judge, and those supporting his position, are mistaken when they claim that ID 'is not science' as 'science does not allow for supernatural causes'. Such an a priori dismissal of supernatural causes renders science less a pursuit of truth, more a pursuit of "generating the best theories that can be formulated subject to the restriction that the theories are naturalistic" (p. 58). Notably, whichever conclusion we draw on this, whether supernatural causes are a part of science or not, isn't strictly relevant to Monton's discussion anyway, as he has already claimed that ID is not inherently theistic or supernatural. But in any case, we might ask if this reading of the situation is fair. Judge Jones did appear to appeal to an overly-ambitious and flawed definition of science, and Monton is right to highlight this. Generally, however, when critics of ID deny that it is 'science', claim that it is 'unscientific', etc., are they literally claiming that it is 'not science'? Or are they rather stating that it is 'not scientific enough'? If an aging parent passes comment on the sound of a popular beat-combo emanating from a teenager's room, "that's not music, that's just noise", do they literally mean that it's not music, or do they rather mean to imply that it does not meet the required standards of tunefulness to qualify as properly being called 'music'? I am inclined to think that critics of ID are doing something very similar, implicitly claiming that there are standards of science that must be met in order to qualify, and ID does not meet these standards. One of the ways that ID fails is in invoking a supernatural cause to fill in the gaps that might appear in a theory; that this gives rise to an accusation of 'not being science' is not due to the dogma that 'supernatural causes are not legitimate in science', but rather that 'supernatural causes should not be invoked unnecessarily in science'.

Monton's claim is that the judge was mistaken in perceiving ID as being inherently theistic, or inherently appealing to supernatural causes. Now whilst this claim might be true in Monton's abstract philosophical context, perhaps a little more sympathy should be extended to the judge, 
and we should recognise that judge Jones made his decision very much within the "cultural war" context that Monton has chosen to ignore. We might consent that ID could be 'not inherently theistic', but the object of the judge's decision is the version of ID as put forward in Of Pandas and People, as this is the book referenced in the "disclaimer" that prompted the case; this version of ID certainly seems to be inherently theistic, given its contextual heritage. Monton might wish to ignore this context to dispassionately assess the arguments, but that option is not really open to the judge.

This reveals a deeper criticism that can be levelled at Monton's book: Is it really fair to deal with the arguments of ID in abstract, in isolation from their context? Monton is clearly aware that this move is controversial, and does spend some time attempting to justify it. Whilst chapter three, "Some Somewhat Plausible Intelligent Design Arguments", manages to stand alone as a sound attempt to do precisely such an abstract appraisal, its conclusions prompt the reader to question whether Monton is really defending "ID" at all. After a consideration of fine-tuning arguments and cosmological arguments, Monton concludes "I consider the cosmological argument a somewhat plausible intelligent design argument" (p. 99), and after an analysis of the stark improbability of life originating from non-life, and a consideration of Nick Bostrom's "simulation argument", Monton concludes "the simulation argument is another example of a somewhat plausible intelligent design argument" (p. 129).

I am tempted to ask whether many proponents of ID would endorse Monton's conclusions. How many ID-ers would consent to their theory being used in support of an argument that claims we are nothing more than a digitised plaything in some alien computer simulation? Again, the arguments of ID could be used in this way, and Monton is entitled to discuss the arguments on these terms; but are they meant to be capable of yielding these conclusions? I just don't think proponents of ID would agree. And if ID proponents do not agree with Monton's conclusions, then Monton's formulation of ID is inaccurate. He is not defending "Intelligent Design", he is defending Bradley Monton's intelligent design; and these two, it seems, are significantly different.

This would not matter so much if it wasn't for his final and concluding chapter four: "Should Intelligent Design Be Taught in School?". It seems 
odd to discuss the appropriate course of action on an issue within a particular context, whilst insisting on a separation of that issue from its context, but this is what Monton seems to do. He assesses the question of whether ID should be taught in schools without reference to certain features of the "cultural war" from which it originates, such as the overtly religious purposes of many ID supporters. Although Monton does make some concessions to recognising the additional contextual considerations that must be taken into account when deliberating on this question, he chooses to focus upon such contextualised questions as:

is it pedagogically good for the children to be taught intelligent design? Will it further the cause of science if children are taught intelligent design? Is it good for society as a whole if intelligent design is taught in school? Is it legally permissible for intelligent design to be taught in school? (p. 136)

These might appear to be concessions to recognising the contextual demands, but underlying all of these questions is one significant problem: The 'intelligent design' under consideration is not "Intelligent Design" as put forward by ID proponents in books such as Of Pandas and People, and The Design of Life; the ID under consideration is Monton's idealised version of ID, abstractly formulated.

So when he outlines his "Six Thoughts on Teaching Intelligent Design" (p. 141), broadly supporting the idea that ID should be taught in schools (briefly put: 1. Inquiry-based learning is better that fact-based learning, and ID could feature in this inquiry. 2. "They're going to hear about it anyway." 3. ID can be taught well, in a non-proselytising way. 4 . Let's teach the philosophy of science. 5. ID arguments are interesting. 6. We should discuss with students what should be taught), a tension between Monton's version of ID and what we might term the real ID becomes apparent; a tension heightened when Monton considers objections to his view.

"We'd be teaching religion!", the objector says to Monton. Monton reasserts that ID is not necessarily inherently religious. I refer to my previous criticisms as to why this is deeply disingenuous, given the actual context in which ID plays out. "We'd be misrepresenting the content of science!"; Monton replies, again, that ID is 'legitimate' science; I reply, again, that though Monton's version of ID may be, the classical version of ID, as found in Of Pandas and People, does not meet the standards 
required to qualify as 'science.' This is not the same as saying it is 'not science, merely that it is 'unscientific'; it is not good enough 'science' to be taught as science to schoolchildren. "We'd be ignoring consensus!" and "We wouldn't be teaching a real controversy!"; Monton responds by pointing out that Newtonian physics is not the consensus view in science either, and yet is considered acceptable to teach; perhaps we can teach 'critical thinking' by considering the controversies of ID, along with the issues of the Newtonian versus the contemporary paradigm? Finally, Monton considers the objection that we'd be asking too much of teachers and students to achieve all of this. His response is a reiteration of an idealised 'inquiry-based learning' scenario, and a claim that denying this option is nothing more than an attempt to preserve the status quo.

Are we to expect every high-school science teacher to be expert enough in the areas of philosophy of science (and religion), theoretical physics, and the post-doctoral level biology necessary for a complete understanding of the proposed 'controversy' surrounding ID? Are we to expect every student to take this on board in the 'correct' way, to at least a similar degree to which they currently take on board the 'fact-based' educational experience? Are we even dealing with this proposal as our option, or are we rather deciding whether Of Pandas and People and The Design of Life are appropriate to use in the classroom?

Which teachers would take up the opportunity to teach ID, and would they teach Monton's philosophical version or the classical theistic version? Irrespective of what could occur, what is actually likely to occur? He concludes his book with a flourish - "I envision my writings being read many years from now, in a cultural climate without the sort of heated rhetoric that we have now, and I picture those readers saying: "yes, Monton had it right."' This reader does not agree. 